\title{
Radio Frequency Power Effect on Charge Density of PECVD-SiN Thin Films
}

\author{
Byungwhan $\mathrm{KIM}^{\dagger}$, Jeong KIM and Hyung Soo UH \\ Department of Electronic Engineering, Sejong University, Seoul 143-747, Korea
}

\begin{abstract}
Charge density is an important film characteristic that determines the quality of film surface passivation. In this study, a prediction model of charge density was constructed by using a neural network and generic algorithm. For a systematic modeling, plasma enhanced chemical vapor deposition process of silicon nitride films was characterized by means of a statistical experimental design. Effects of parameters under various radio frequency (rf) powers were examined under various plasma conditions. An increase in charge density was observed with increasing rf power over the entire range of $\mathrm{SiH}_{4}$ flow rate as well as at lower $\mathrm{N}_{2}$ flow rates or pressures. The effect of $\mathrm{SiH}_{4}$ flow rate on charge density was opposite to that for $\mathrm{N}_{2}$ flow rate given rf powers. For the variations in $\mathrm{N}_{2}$ or $\mathrm{SiH}_{4}$ flow rate, charge density seemed to be strongly correlated to $\mathrm{N} / \mathrm{Si}$ ratio. Under the variations in pressure or $\mathrm{N}_{2}$ flow rate, maintaining a lower pressure was beneficial in achieving a higher charge density. A pronounced rf power effect at smaller grain size was expected.
\end{abstract}

[Received June 28, 2007; Accepted September 20, 2007]

Key-words : PECVD, Neural network, Charge density, Silicon nitride

1. Introduction

Silicon nitride (SiN) thin films are widely used in manufacturing solar cells [1-2]. Plasma enhanced chemical vapor deposition (PECVD) process is widely utilized in SiN deposition due to a high film quality. ${ }^{1)-4)}$ Understanding and control of PECVD of SiN films are highly difficult due to the complex reactions between plasma and several process or equipment parameters. To overcome this difficulty, neural network has been applied to build a deposition rate, or a refractive index model of SiN deposition process. ${ }^{5), 6)}$ Another important film characteristic is charge density, which determines the quality of surface passivation. Despite this importance, little studies on the charge density were conducted at various plasma conditions.

In this study, a charge density of SiN film was modeled by using a neural network called generalized regression neural network (GRNN). ${ }^{7)}$ Apart from the deposition process, the GRNN has been applied to model plasma etch processes. ${ }^{8), 9)}$ The prediction performance of GRNN was optimized by using a genetic algorithm $(\mathrm{GA}){ }^{10)}$ For a systematic modeling, the plasma enhanced chemical vapor deposition (PECVD) process was characterized by means of a statistical experimental design. The effects of process parameters on the charge density were examined by exploring 3D plots generated from an optimized prediction model.

\section{Experimental details}

SiN films were deposited by using a Plasma-Therm 700 series batch reactor operating at $13.56 \mathrm{MHz}$. The distance between the electrodes was $0.0223 \mathrm{~m}$ and the electrode diameter was $0.279 \mathrm{~m}$. The PECVD process was characterized by the face-centered central composite circumscribed experiment, consisted of $2^{6-1}$ fractional experiment and 12 axial points. ${ }^{11)}$ The experimental parameters and their low and high values presented in previous studies $[5-6]$. The resulting 33 experiments, including one experiment corresponding to one center point, were used to train the GRNN. Prediction performance of the trained GRNN was tested with additional 12 experiments not pertaining to the training data. Four-inch, float zone p-type silicon wafers of (100) orientation with a resistivity of $0.02 \Omega-\mathrm{m}$, were used as the substrate. During the

\footnotetext{
${ }^{\dagger}$ Corresponding author; E-mail; kbwhan@sejong.ac.kr
}

deposition, $\mathrm{SiH}_{4}$ was diluted to $2 \%$ in nitrogen. Approximately $0.05 \mu \mathrm{m}$ silicon nitride was deposited. The charge density was measured by $C-V$ measurements.

\section{Results}

\subsection{Model optimization}

Conventionally, the prediction performance of GRNN model is optimized by adjusting the training factor called "spread." This implies that all spreads for all functions in the pattern layer have one, optimized value. However, it is expected that better prediction may be achieved by adopting multiparameterized spreads. A related approach was applied to model a deposition rate. ${ }^{5), 8), 9)}$ In this study, this scheme was adopted and a set of optimal spreads was obtained by applying GA. For the GA parameters, the size of initial population and number of generation were set to the same 100 . The crossover and mutation probabilities were set to 0.95 and 0.05 , respectively. The fitness function was defined in terms of the training error as

$$
F=\frac{1}{1+\mathrm{RMSE}_{\text {train }}}
$$

where the RMSE $\mathrm{E}_{\text {train }}$ was measured with the training data composed of 33 experiments. Here the RMSE represents the root mean square error (RMSE). The range of spreads was varied from 0.2 to 1.2 . For each spread range, the prediction performance of GA-GRNN is depicted in Fig. 1. As seen in Fig. 1, the smallest prediction error is obtained at a spread range of 0.3 and the corresponding error is $0.72\left(\times 10^{16} / \mathrm{m}^{2}\right)$.

3.2 Effect of rf power and $\mathrm{SiH}_{4}$ flow rate

To examine the parameter effects on charge density, several 3D plots were generated from the optimized model. Figure 2 shows a charge density as a function of $\mathrm{rf}$ power and $\mathrm{SiH}_{4}$ flow rates. The pressure, temperature, and $\mathrm{N}_{2}$ and $\mathrm{NH}_{3}$ flow rates were set to $119.7 \mathrm{~Pa}, 523 \mathrm{~K}$, and 835 and $2.0\left(\times 10^{-8} \mathrm{~m}^{3} / \mathrm{s}\right)$, respectively. In Fig. 2, the charge density slightly increases with increasing the power. This may stem from the promoted surface reactions by energetic ions. The increase in charge density is supported by the experimental data collected at $367.4\left(\times 10^{-8} \mathrm{~m}^{3} / \mathrm{s}\right) \mathrm{SiH}_{4}$ flow rates, where the charge density increased from 2.27 to $3.12\left(10^{16} / \mathrm{m}^{2}\right)$ with increasing the power from 20 to $40 \mathrm{~W}$. The increase can be attributed to the formation of a denser, homogeneous film at the enhanced ion 


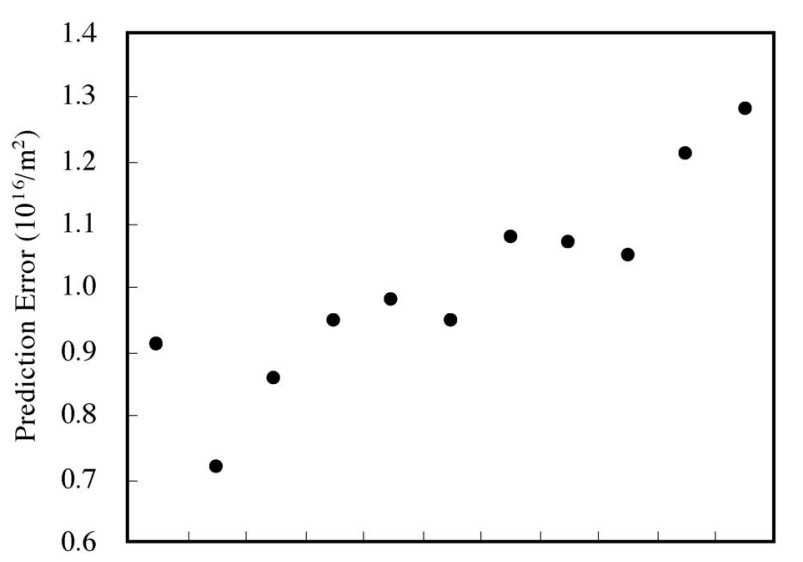

$\begin{array}{llllllllllll}0.2 & 0.3 & 0.4 & 0.5 & 0.6 & 0.7 & 0.8 & 0.9 & 1.0 & 1.1 & 1.2\end{array}$

Spread Range

Fig. 1. Prediction performance of GA-GRNN models as a function of spread range.

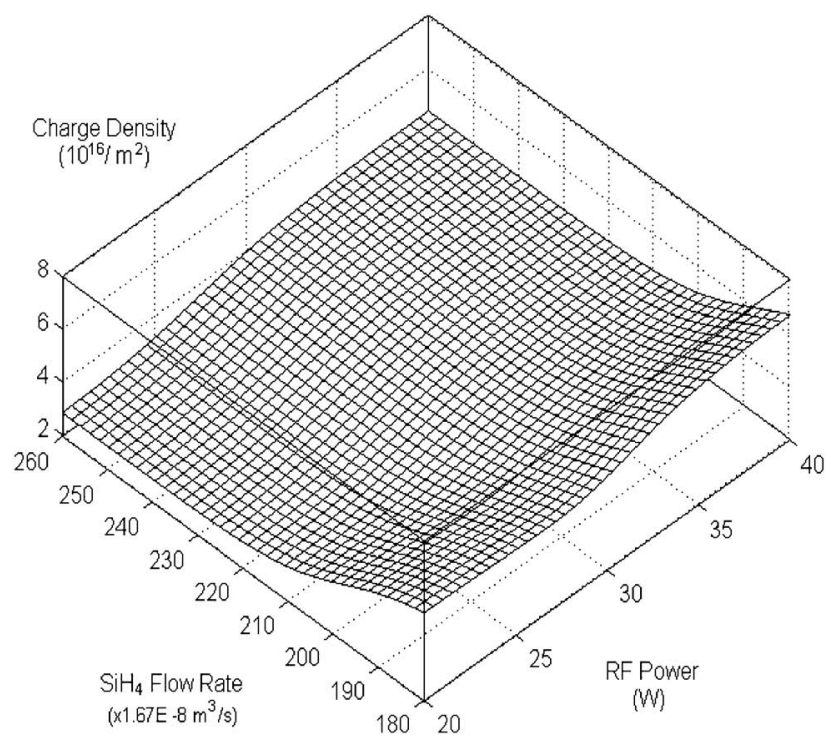

Fig. 2. Charge density as a function of rf power and $\mathrm{SiH}_{4}$ flow rate.

bombardment. Compared to $\mathrm{N}-\mathrm{H}$ bonds, $\mathrm{Si}-\mathrm{H}$ bonds are likely to be more easily broken by ion bombardment due to a lower bond strength of $299.2 \mathrm{~kJ} / \mathrm{mol}$. The resulting increase in $\mathrm{Si}$ concentration at higher $\mathrm{rf}$ powers may explain the creation of denser and more homogenous film. Also, the expected increase in $\mathrm{Si} / \mathrm{N}$ ratio was predicted particularly at higher $\mathrm{SiH}_{4}$ flow rates in the previous refractive index model. ${ }^{12)}$ Meanwhile, the increase is observed over the entire range of $\mathrm{SiH}_{4}$ flow rates, indicating that the power effect is little affected by the variations in $\mathrm{SiH}_{4}$ flow rates.

As shown in Fig. 2, the charge density is seen to decrease with increasing the $\mathrm{SiH}_{4}$ flow rates and then varies little despite the increase in $\mathrm{SiH}_{4}$ flow rate. This is partly supported by the experimental data conducted at $30 \mathrm{~W}$, where the charge density decreased from 6.23 to $4.31\left(10^{16} / \mathrm{m}^{2}\right)$ as the $\mathrm{SiH}_{4}$ flow rates increased from 300.6 to $434.2\left(\times 10^{-8} \mathrm{~m}^{3} / \mathrm{s}\right)$, respectively. It should be noted that increasing $\mathrm{SiH}_{4}$ flow rate at either 13.56 or $40 \mathrm{MHz}$ decreased $(\mathrm{N}-\mathrm{H}) /(\mathrm{Si}-\mathrm{H})$ ratio. ${ }^{13)}$

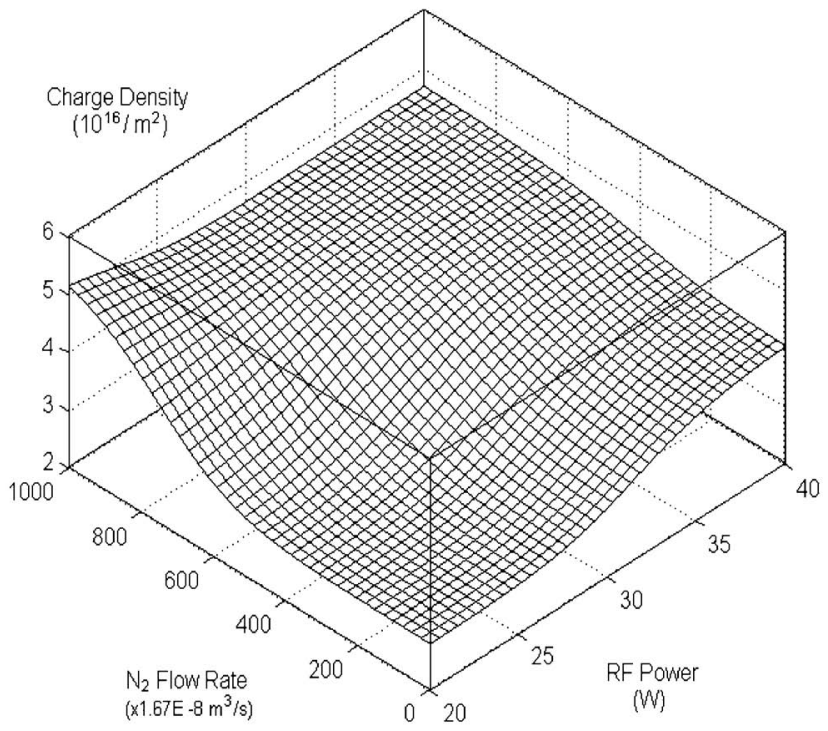

Fig. 3. Charge density as a function of $\mathrm{rf}$ power and $\mathrm{N}_{2}$ flow rate.

\subsection{Effect of rf power and $\mathrm{N}_{2}$ flow rate}

Effects of $\mathrm{N}_{2}$ flow rates on the charge density as a function of $\mathrm{rf}$ power are shown in Fig. 3. The pressure, temperature, and $\mathrm{SiH}_{4}$ and $\mathrm{NH}_{3}$ flow rates were set to $119.7 \mathrm{~Pa}, 523 \mathrm{~K}$, and 367.4 and $2.0\left(\times 10^{-8} \mathrm{~m}^{3} / \mathrm{s}\right)$, respectively. As shown in Fig. 3, increasing $\mathrm{N}^{2}$ flow rate increases the charge density. This is noticed over the entire range of $\mathrm{rf}$ powers. This implies that the effect of $\mathrm{N}_{2}$ flow rate is independent of rf powers. It can be easily expected that increasing $\mathrm{N}_{2}$ flow rate increases the N/Si ratio. This is supported by the refractive index model. ${ }^{12)}$ From these, the charge density variation is closely related to N/Si ratio as $\mathrm{N}_{2}$ flow rate is varied. Interestingly, this is identical to that obtained for the variations in $\mathrm{SiH}_{4}$ flow rates. In view of film's microstructure, it was once observed in a $\mathrm{NH}_{3}-\mathrm{SiH}_{4}$ plasma that increasing $\mathrm{NH}_{3}$ flow rate particularly at higher $\mathrm{rf}$ powers increased the surface roughness of SiN film. ${ }^{14}$ This was explained by the promoted surface reactions by more energetic $\mathrm{N}_{2}{ }^{+}$ions. A similar increase in surface roughness with increasing $\mathrm{N}_{2}$ flow rates in this plasma adopted here is expected from the enhanced surface reactions by larger $\mathrm{N}_{2}{ }^{+}$ ions. Fortunately, this is supported by a recent experiment conducted in a pulsed magnetron sputtering. ${ }^{15)}$ In this experiment, a larger surface roughness was observed at higher $\mathrm{N}_{2}$ flow rates. Another study conduced at extremely lower ratios of $\mathrm{NH}_{3} / \mathrm{SiH}_{4}$ of less than 0.20 reported a turnover in the surface roughness variation with the ratio. ${ }^{16)}$

As shown in Fig. 3, the effects of rf power are quite different depending on $\mathrm{N}_{2}$ flow rates. Increasing the $\mathrm{rf}$ power at lower $\mathrm{N}_{2}$ flow rates considerably increases the charge density. The supporting experiments are shown in Table 1. In Table 1, the effect of different temperatures can be disregarded due to the little interaction between the temperature and $\mathrm{N}_{2}$ flow rate as once was ascertained from the model. As once observed in a $\mathrm{NH}_{3}-\mathrm{SiH}_{4}$ plasma, ${ }^{14)}$ an increase in surface roughness at higher powers is expected since more energetic $\mathrm{N}_{2}{ }^{+}$ions promote surface reactions. Meanwhile, the power effect at higher $\mathrm{N}_{2}$ flow rates seems to be insignificant. The supporting experiments are shown in Table 2. The little variation with the $\mathrm{rf}$ power indicates a little impact of ion bombardment. From the standpoint of grain size, $\mathrm{N}_{2}$ addition was reported to speed up the growth of grains by inducing fewer nucleation. ${ }^{17)}$ This 
Table 1. Experimental Data Supporting the Rf Power Effect on Charge Density at $0\left(1.67 \times 10^{-8} \mathrm{~m}^{3} / \mathrm{s}\right) \mathrm{N}_{2}$ Flow Rate

\begin{tabular}{cccccc}
\hline $\begin{array}{c}\text { Temperature } \\
(\mathrm{K})\end{array}$ & $\begin{array}{c}\text { Power } \\
(\mathrm{W})\end{array}$ & $\begin{array}{c}\text { Pressure } \\
(\mathrm{Pa})\end{array}$ & $\begin{array}{c}\mathrm{NH}_{3} \text { Flow Rate } \\
\left(\times 10^{-8} \mathrm{~m}^{3} / \mathrm{s}\right)\end{array}$ & $\begin{array}{c}\mathrm{SiH}_{4} \text { Flow Rate } \\
\left(\times 10^{-8} \mathrm{~m}^{3} / \mathrm{s}\right)\end{array}$ & $\begin{array}{c}\text { Charge Density } \\
\left(10^{16} / \mathrm{m}^{2}\right)\end{array}$ \\
\hline 573 & 20 & 159.6 & 2.34 & 300.6 & 3.47 \\
473 & 40 & 159.6 & 2.34 & 300.6 & 7.81 \\
\hline 573 & 20 & 159.6 & 2.34 & 434.2 & 6.21 \\
473 & 40 & 159.6 & 2.34 & 434.2 & 9.74 \\
\hline
\end{tabular}

Table 2. Experimental Data Supporting the Rf Power Effect on Charge Density at $1670\left(\times 10^{-8} \mathrm{~m}^{3} / \mathrm{s}\right) \mathrm{N}_{2}$ Flow Rate

\begin{tabular}{cccccc}
\hline $\begin{array}{c}\text { Temperature } \\
(\mathrm{K})\end{array}$ & $\begin{array}{c}\text { Power } \\
(\mathrm{W})\end{array}$ & $\begin{array}{c}\text { Pressure } \\
(\mathrm{Pa})\end{array}$ & $\begin{array}{c}\mathrm{NH}_{3} \text { Flow Rate } \\
\left(\times 10^{-8} \mathrm{~m}^{3} / \mathrm{s}\right)\end{array}$ & $\begin{array}{c}\mathrm{SiH}_{4} \text { Flow Rate } \\
\left(\times 10^{-8} \mathrm{~m}^{3} / \mathrm{s}\right)\end{array}$ & $\begin{array}{c}\text { Charge Density } \\
\left(10^{16} / \mathrm{m}^{2}\right)\end{array}$ \\
\hline 573 & 20 & 79.8 & 1.67 & 300.6 & 5.07 \\
473 & 40 & 79.8 & 1.67 & 300.6 & 5.55 \\
\hline 573 & 20 & 79.8 & 1.67 & 434.2 & 3.27 \\
473 & 40 & 79.8 & 1.67 & 434.2 & 3.5 \\
\hline
\end{tabular}

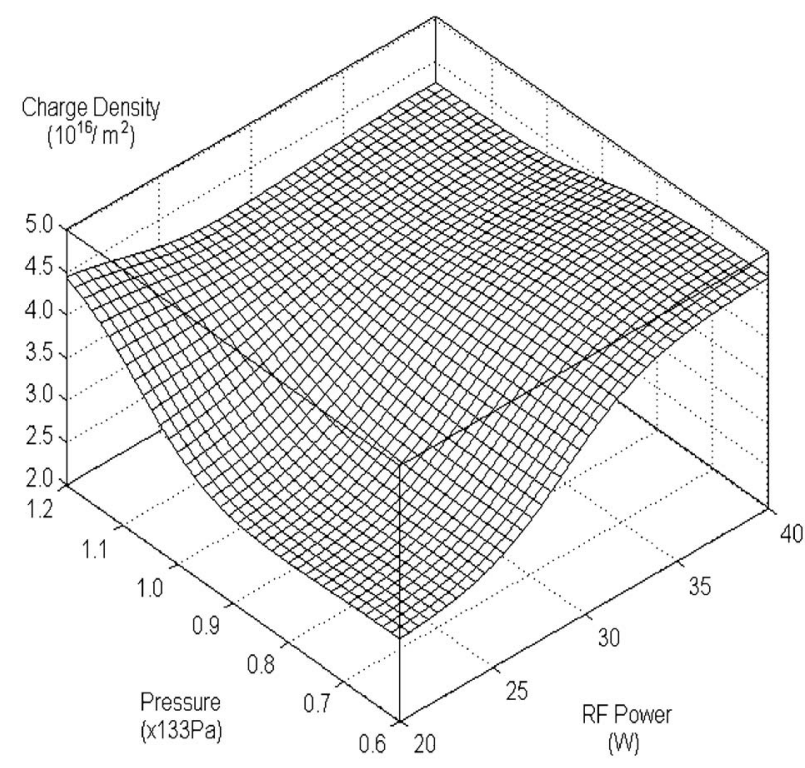

Fig. 4. Charge density as a function of rf power and pressure.

enables a differentiation of $\mathrm{rf}$ power effect depending on the grain size. Namely, the power effect on charge density at lower $\mathrm{N}_{2}$ flow rates (i.e., smaller grain sizes) is maintained with increasing the $\mathrm{rf}$ power as shown in Fig. 3. In contrast, this does not happen at higher $\mathrm{N}_{2}$ flow rates (i.e., larger grain sizes). Therefore, it is revealed that charge density can be controlled as a function of $\mathrm{rf}$ power only at smaller grain sizes.

\subsection{Effect of rf power and pressure}

Figure 4 shows the effects of pressure on charge density as a function of $\mathrm{rf}$ power. The temperature, $\mathrm{N}_{2}, \mathrm{SiH}_{4}$, and $\mathrm{NH}_{3}$ flow rates were set to $523 \mathrm{~K}, 500,220$, and $1.2\left(\times 10^{-8} \mathrm{~m}^{3} / \mathrm{s}\right)$, respectively. As seen in Fig. 4, the power effect is similar to that already noticed in Fig. 3. The effect of pressure on the charge density is quite different depending on the power level. The pressure effect on the charge density seems to be insignificant at higher powers. This is supported partly by a few increase of charge density form 4.35 at 0.6 to $4.74\left(10^{16} / \mathrm{m}^{2}\right)$ at $159.6 \mathrm{~Pa}$. The other parameters were set at their default values stated earlier. In contrast, increasing the pressure at the powers less than about $30 \mathrm{~W}$ appears to increase the charge density. This can be verified partly by the experimental data shown in Table 3. In evaluating the data in Table 3, the effect of $\mathrm{N}_{2}$ flow rate was not taken into account since it was little affected by the power levels as already observed in Fig. 3. The noticeably increased charge density at higher pressures can be understood by the expected increased incorporation of $\mathrm{N}$ into the film due to the enhanced collision rate at higher pressure. This is supported by the refractive index variation at the same plasma conditions. ${ }^{18)}$ Actually, the refractive index increasing with the pressure was considerably decreased at higher pressures. This is a clear indicative of a larger concentration of $\mathrm{N}$ relatively than $\mathrm{Si}$.

\section{Conclusions}

In this paper, a prediction model of charge density of silicon nitride film was constructed by using GRNN and GA. Also, a refractive index model was utilized to support and validate the interpretation of charge density model. The PECVD process was characterized by means of statistical experimental design. The effects of three parameters $\left(\mathrm{SiH}_{4}\right.$ flow rate, $\mathrm{N}_{2}$ flow rate, and pressure) were examined under various rf powers. Implications on microstructures were also investigated. Either $\mathrm{N}_{2}$ or $\mathrm{SiH}_{4}$ flow rate seemed to affect charge density almost independently of $\mathrm{rf}$ powers. The rf power effect was noticeable at lower levels of $\mathrm{N}_{2}$ flow rate or pressure. The effect of gas flow rates could be explained in terms of $\mathrm{Si} / \mathrm{N}$ ratio.

Acknowledgments This work was supported by Grand No. R11-2000-086-0000-0 from the Center of Excellency Program of the KOSEF, MOST, and partly by the MIC (Ministry of Information and Communication), Korea, under the ITRC (Information Technology Research Center) support program supervised by the IITA(Institute of Information Technology Advancement) (IITA-2006-C109006030030).

\section{References}

1) C. Ko, J. Joo and M. Han, J. Kor. Phys. Soc., 48, 1277-1280 (2006).

2) B. Karunagaran, J. P. Jeong, S. Nagarajan, S. J. Chung and E.-K. Suh, J. Kor. Phys. Soc., 48, 1250-1254 (2006).

3) B. F. Hanyaloglu and E. S. Aydil, J. Vac. Sci. Technol. A, 16, 2794-2803 (1998).

4) J. W. Lee, K. D. Maclenzie, D. Johnson, J. N. Sasserath, S. J. 
Table 3. Experimental Data Supporting the Pressure Effect on Charge density at $20 \mathrm{~W}$ Rf Power

\begin{tabular}{cccccc}
\hline $\begin{array}{c}\text { Temperature } \\
(\mathrm{K})\end{array}$ & $\begin{array}{c}\text { Power } \\
(\mathrm{W})\end{array}$ & $\begin{array}{c}\text { Pressure } \\
(\mathrm{Pa})\end{array}$ & $\begin{array}{c}\mathrm{NH}_{3} \text { Flow Rate } \\
\left(\times 10^{-8} \mathrm{~m}^{3} / \mathrm{s}\right)\end{array}$ & $\begin{array}{c}\mathrm{SiH}_{4} \text { Flow Rate } \\
\left(\times 10^{-8} \mathrm{~m}^{3} / \mathrm{s}\right)\end{array}$ & $\begin{array}{c}\text { Charge Density } \\
\left(10^{16} / \mathrm{m}^{2}\right)\end{array}$ \\
\hline 573 & 40 & 79.8 & 2.34 & 300.6 & 4.75 \\
573 & 40 & 159.6 & 2.34 & 300.6 & 8.66 \\
\hline 573 & 20 & 79.8 & 1.67 & 434.2 & 3.27 \\
573 & 20 & 159.6 & 1.67 & 434.2 & 5.69 \\
\hline
\end{tabular}

Pearton and F. Ren, J. Electrochem. Soc., 147, 1481-1486 (2000).

5) B. Kim, K. Park and D. Lee, Plasma Sour. Sci. Technol., 14, 83-88 (2005).

6) B. Kim and W. S. Hong, IEEE Trans. Plasma Sci., 32, 84-89 (2004).

7) D. F. Specht, IEEE Trans. Neural Network, 2, 568-576 (1991).

8) B. Kim and B. T. Lee, J. Vac. Sci. Technol. A, 22, 2517-2522 (2004).

9) B. Kim and K. H. Kim, Appl. Surf. Sci., 222, 17-22 (2004).

10) D. E. Goldberg, "Genetic Algorithms in Search, Optimization \& Machine Learning,” Addison Wesley, 1989.

11) D. C. Mongomery, "Design and Analysis of Experiments," John Wiley \& Sons (1991).
12) B. Kim, D. W. Kim and S. S. Han, Vacuum 72, 385-392 (2004).

13) K. Takechi, T. Takagi and S. Kaneko, Jpn. J. Appl. Phys., 37, 1996-2001 (1998).

14) Y. B. Park and S. W. Rhee, J. Mat. Sci.: Mat. in Electronics, 12, 515-522 (2001).

15) Z. Q. Yao, P. Yang, N. Huang, H. Sun, G. J. Wan, Y. X. Leng and J. Y. Chen, Nucl. Instr. and Meth. B, 240, 741-751 (2005).

16) P. Temple-Boyer, L. Jaiabert and L. Masarotto, J. Vac. Sci. Technol. A, 18, 2389-2393 (2000).

17) Z. Liang, J. Shen, J. Li and N. Xu, Solar Energy, 72, 505-510 (2002).

18) B. Kim, S. Kim and W. S. Hong, Plasma Chem. Plasma Proc., 24, 29-40 (2004). 